Lones, D. P.,'Rainbow, C. \& Woodwand, J. D. (1958). J. gen. Microbiol. 19, 146-160

\title{
A Diazotizable Amine Produced by Yeast: its Chemical Nature and Factors Affecting its Accumulation
}

\author{
By D. P. LONES, C. RAINBOW AND J. D. WOODWARD \\ Department of Applied Biochemistry, University of Birmingham
}

\begin{abstract}
SUMMARY: The effect of area:volume ratio and composition of medium on the accumulation of diazotizable amine ('amine') and hypoxanthine by yeast 47 growing in biotin-deficient medium are reported. The 'amine', isolated from culture filtrates by mercury precipitation and separation on ion exchange resins, gave the Pauly reaction for imidazoles: on acid hydrolysis it yielded ribose, glycine, ammonia and formic acid, but no phosphate. These properties are consistent with the view that the 'amine' is 5-amino-imidazole riboside or a closely related compound. When the growth medium contained $500 \mu \mathrm{g}$. L-aspartic acid/ml., instead of 'amine' and hypoxanthine, substances accumulated which on hydrolysis yielded adenine as the only purine. 'Amine' accumulation by yeast 47 may be a symptom of a derangement of purine metabolism resulting from a biotin-conditioned block in aspartate synthesis.
\end{abstract}

Previous papers from this laboratory (Chamberlain, Cutts \& Rainbow, 1952; Chamberlain \& Rainbow, 1954) reported that a diazotizable amine ('amine') and hypoxanthine accumulated in culture filtrates of Saccharomyces cerevisiae (yeast 47) after growth in a biotin-deficient defined medium containing L-methionine; 'amine' accumulation was invariably associated with the formation of a pink pigment. It was also shown that inclusion of adenine or aspartate in the medium prevented the accumulation of 'amine', the formation of which was interpreted as being symptomatic of a derangement in purine metabolism conditioned by biotin deficiency. The present paper reports studies of some factors which affect the formation of 'amine' and hypoxanthine by yeast 47, a method of preparing purified 'amine' and a preliminary study of the chemical nature of 'amine'.

\section{METHODS}

\section{Test organisms and preparation of inocula}

Saccharomyces cerevisiae (yeast 47) was used for all experiments on the accumulation of 'amine', and cultures were maintained on malt agar slopes as described by Chamberlain \& Rainbow (1954). Inocula were prepared by transferring organisms from a slope to $6 \mathrm{ml}$. of defined medium and incubating at $28^{\circ}$ for $16-20 \mathrm{hr}$. The organisms were then centrifuged off, washed three times with $6 \mathrm{ml}$. portions of sterile, $0.85 \%$ saline and resuspended in a further $6 \mathrm{ml}$. of the saline for use in inoculation.

The strain of Lactobacillus brevis (L4) used for the detection of glycine and serine, and for the microbiological assay of glycine was that described by Moore \& Rainbow (1955): it was maintained, and inocula were prepared, as described by them. 


\section{Media}

Saccharomyces cerevisiae. Experiments with yeast 477 were carried out either in the defined medium I, having the composition given by Chamberlain \& Rainbow (1954) or in medium II, differing from medium I in containing 10 times less $\mathrm{CaCl}_{2} \cdot 6 \mathrm{H}_{2} \mathrm{O}(25 \mu \mathrm{g} . / \mathrm{ml}$.). Both media contained $20 \mu \mu \mathrm{g}$. of $\mathrm{D}$-biotin and $500 \mu \mathrm{g}$. of DL-methionine $/ \mathrm{ml}$. However, for the preparation of inocula, methionine was omitted and the concentration of biotin was increased to $1 \mathrm{~m} \mu \mathrm{g} . / \mathrm{ml}$.

Lactobacillus brevis L 4. The medium described by Chamberlain \& Rainbow (1954) was used with the following modifications: (a) $2 \%$ glucose was replaced by a mixture of $1 \%$ each of glucose and L-arabinose; $(b)$ sodium acetate was omitted; (c) $10 \mu \mathrm{g}$. each of adenine and guanine were added $/ \mathrm{ml}$. of medium; (d) casein acid hydrolysate was replaced by a mixture of amino acids as follows (mg./100 ml.): DL-alanine, 20; L-arginine hydrochloride, 31; L-asparagine, 10; L-aspartic acid, 7 ; L-cystine, 5; glycine, 10; L-glutamic acid hydrochloride, 18; L-histidine hydrochloride, 6; DL-isoleucine, 19; L-leucine, 16; L-lysine hydrochloride, 18; DL-methionine, 7; DL-phenylalanine, 16; L-proline, 49; DIserine, 15; DL-threonine, 21 ; DL-tryptophan 9; L-tyrosine, 9 and DL-valine, 31. For the detection of serine, DL-serine was omitted and for the detection and assay of glycine, glycine was omitted from this basal medium.

\section{Growth of cultures}

Tube cultures $(6 \mathrm{ml}$.) were carried out as described by Northam \& Norris (1951). Incubation was at $21^{\circ}$ or $25^{\circ}$ (yeast 47 ) or at $28^{\circ}(\mathrm{L} 4)$. Each tube was inoculated with one drop (c. $0.03 \mathrm{ml}$.) of suspension. Growth was measured as dry weight of yeast $47 / \mathrm{ml}$. derived from Spekker (Hilger, London) readings by reference to a previously determined calibration curve.

Larger cultures (40-700 ml.) of yeast 47 were grown in conical flasks or, in most cases, in 'Glaxo' culture vessels having a capacity of $2.5 \mathrm{l}$. These cultures were inoculated with a volume of inoculum proportionately larger than that used in tube tests (e.g. $3 \mathrm{ml}$. of suspension for a $500 \mathrm{ml}$. culture) except as indicated in the Results section.

\section{Analytical methods}

Diazotizable amine ('amine'). This was determined by the Bratton \& Marshall procedure as described by Chamberlain \& Rainbow (1954). Values quoted are the Spekker readings thus obtained.

Amino acids. These were detected qualitatively by paper chromatography (Chamberlain \& Rainbow, 1954). Glycine and serine were distinguished with $\mathrm{L} 4$, which requires both amino acids for growth during the first $72 \mathrm{hr}$. Glycine in 'amine' hydrolysates was assayed by a similar technique in a medium to which serine was added; the approximate amount of glycine in the test sample was obtained by reference to a standard curve obtained with known amounts of glycine.

Imidazole derivatives. These compounds were detected by Koessler \& 
Hanke's (1919) modification of the Pauly reaction when in solution or by the modification introduced by Ames \& Mitchell (1952) when on paper chromatograms.

Purine derivatives. After separation by paper chromatography purines were detected by ultraviolet photography. In culture filtrates, they were determined by ultraviolet spectrophotometry. These procedures were carried out as described by Chamberlain \& Rainbow (1954).

Ion exchange. Conventional techniques were used, the resins having been taken through a depletion and regeneration cycle before use in the columns. In the process of purification of 'amine', the weakly acidic cation exchanger, Amberlite IRC-50, in the hydrogen form, and the weakly basic anion exchanger Amberlite IR-4 B, in the free base form, were used. Further details are given in the Results section.

Quantitative analyses of 'amine'. Preparations of 'purified amine' were dried in vacuo to constant weight at a temperature below $40^{\circ}$. The dried 'amine' was then dissolved in $1.00 \mathrm{ml}$. of distilled water and a sample of $15 \mu \mathrm{l}$. removed and diluted to $6.0 \mathrm{ml}$. for determination of diazotizable amine.

The ash was determined in a second portion $(250 \mu \mathrm{l}$.) of the solution of 'purified amine'; it was carefully evaporated to dryness on a piece of tared platinum foil and then heated to dull red heat until constant weight was attained.

Pentose was determined by Drury's (1948) orcinol method. Optical densities of the colour produced by the reaction were read at $670 \mathrm{~m} \mu$ in the Unicam S.P. 500 quartz spectrophotometer (Unicam Instruments Ltd, Cambridge), the content of pentose in test solutions being calculated by reference to a calibration curve constructed by submitting known amounts of D-ribose to the same procedure. For determinations on the above solution of 'purified amine', samples of $10 \mu \mathrm{l}$. were used.

The remaining 'amine' solution was hydrolysed by heating on a boiling water bath for $2 \mathrm{hr}$. with an equal volume of $4 \mathrm{~N}^{-} \mathrm{H}_{2} \mathrm{SO}_{4}$. Determinations as follows were made on the hydrolysate.

Total nitrogen was determined on samples $(0.10 \mathrm{or} \mathbf{0 . 2 0} \mathrm{ml}$.) of the hydrolysate by a conventional micro-Kjeldahl procedure.

For the determination of formic acid, $\mathbf{0 . 2 0} \mathrm{ml}$. of 'amine' hydrolysate was introduced into the micro-Kjeldahl apparatus, followed by $1 \mathrm{ml}$. of syrupy

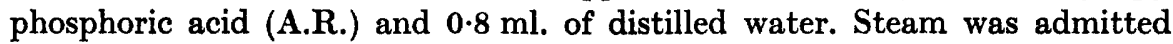
and $20 \mathrm{ml}$. of distillate collected. To the distillate was added $0.25 \mathrm{ml}$. of $0 \cdot 1 \mathrm{~N}-\mathrm{Na}_{2} \mathrm{CO}_{3}$ solution and $2.50 \mathrm{ml}$. of standard $\mathrm{KMnO}_{4}$ solution $(0.02 \mathrm{~N})$ and the mixture was heated for $15 \mathrm{~min}$. at $80-90^{\circ}$. After acidification with $0 \cdot 4 \mathrm{ml}$. of $10 \mathrm{~N}-\mathrm{H}_{2} \mathrm{SO}_{4}$, an excess $(3.00 \mathrm{ml}$.) of $0.02 \mathrm{~N}$-sodium oxalate solution was added and the excess determined by titration against standard $(0.02 \mathrm{~N}) \mathrm{KMnO}_{4}$ solution. From the difference between this titre and that obtained when $0.20 \mathrm{ml}$. of distilled water was substituted for 'amine' hydrolysate in the same procedure, the amount of formic acid in the test sample was calculated. This procedure gave almost theoretical results when applied to solutions containing known amounts of formic acid. 
Ammonia-nitrogen was determined on the residue remaining after distilling off the formic acid; the solution remaining in the micro-Kjeldahl apparatus was made alkaline by the addition of $4 \mathrm{ml}$. of $40 \% \mathrm{NaOH}$ solution and distillation was repeated. The ammonia distilled was trapped in $5 \mathrm{ml}$. of saturated boric acid solution ( $8 \mathrm{ml}$. of distillate being collected) and the ammonia present titrated against standard (0.01 N) HCl. Titres were corrected for the appropriate blank determinations.

Glycine-nitrogen was determined as the difference between total-nitrogen and ammonia-nitrogen.

\section{RESULTS}

\section{Factors influencing the accumulation of 'amine' and hypoxanthine}

Rate of formation of 'amine' and hypoxanthine. This was examined by growing yeast 47 in $40 \mathrm{ml}$. portions of medium $\mathrm{I}$ in $100 \mathrm{ml}$. conical flasks. One culture was removed daily for determination of 'amine' and hypoxanthine, so that the changes in area: volume ratio entailed by successive withdrawals of samples from a single culture was avoided. The results (Fig. 1) showed that 'amine' concentration reached a maximum after 5 days and diminished thereafter, whereas hypoxanthine continued to accumulate throughout the experiment ( 9 days), its concentration after 5 days being $c .18 \mu \mathrm{g} . / \mathrm{ml}$.

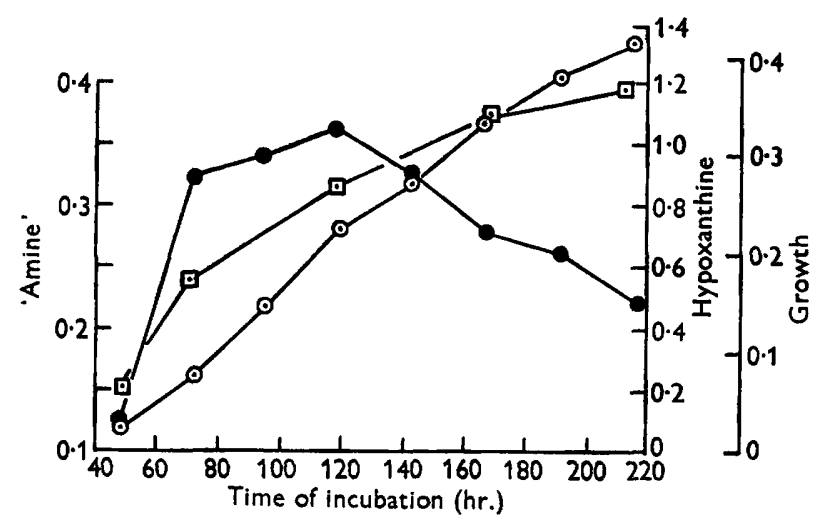

Fig. 1. Rate of formation of 'amine' and hypoxanthine in $40 \mathrm{ml}$. cultures of yeast 47 grown at $21^{\circ}$; 9 , 'amine' as Spekker readings of the colour produced from unpurified culture filtrates in the diazotization reaction; $\odot$, hypoxanthine as optical density at $250 \mathrm{~m} \mu$; $\square$, growth as mg. dry yeast weight/ml.

Effect of the ratio of surface to volume. For cultures grown in medium $\mathrm{I}$ in culture vessels, the amount of 'amine' $/ \mathrm{ml}$. of culture filtrate increased as the area/volume ratio was increased from 0.32 to $0 \cdot 76$, but hypoxanthine accumulation was unaffected. For the preparation of 'purified amine', $500 \mathrm{ml}$. in a culture flask was chosen as a convenient culture volume consistent with high yields of 'amine'.

Concentration of media constituents. The yield of 'amine' was decreased $19 \%$ by decreasing the concentration of glucose to one-tenth; this paralleled the 
decrease in growth. A similar decrease in concentration of $p$-AB reduced the yield of 'amine' and hypoxanthine by $c 25 \%$ without affecting growth A tenfold diminution in the concentration of trace salts was accompanied by a decrease of $11 \%$ in the yield of 'amine', while diminution of the concentration of $\mathrm{CaCl}_{2}$ increased the yield by $13 \%$ and that of hypoxanthine by $10 \%$ without affecting growth. Medium II contained $\mathrm{Ca}$ at this reduced level and was used to obtain material for the preparation of purified amine.

\section{Table 1. Effect of organic acids on 'amine' formation}

Tube tests at $25^{\circ}$ for 4 days; organic acid supplements were adjusted to $\mathrm{pH}$ 5.0 with KOH solution and (except lactate) tested at a concentration of $0.05 \mathrm{M}$; concentration of lactate as in medium I; growth [column (1)] as mg. yeast dry weight/ml.; column (2) shows 'amine' as Spekker readings of the colour of diazotized and coupled 'amine'; column (3) shows 'amine'/mg. yeast dry weight = column (2) /column (1).

\begin{tabular}{|c|c|c|c|c|c|c|}
\hline \multirow[b]{3}{*}{ Acid supplement } & \multicolumn{3}{|c|}{ Medium I } & \multicolumn{3}{|c|}{ Medium I without lactate } \\
\hline & \multirow[b]{2}{*}{$\begin{array}{c}\text { Growth } \\
\text { (1) }\end{array}$} & \multicolumn{2}{|c|}{ 'Amine' } & \multirow[b]{2}{*}{$\begin{array}{c}\text { Growth } \\
\text { (1) }\end{array}$} & \multicolumn{2}{|c|}{ 'Amine' } \\
\hline & & (2) & (3) & & (2) & (3) \\
\hline None & 0.294 & 0.197 & 0.67 & 0.260 & 0.292 & $1 \cdot 12$ \\
\hline Acetic & 0.260 & 0.054 & $\mathbf{0} \cdot \mathbf{2 1}$ & $0 \cdot 242$ & 0.098 & $0 \cdot 41$ \\
\hline Cisaconitic & 0.268 & $0 \cdot 100$ & $0 \cdot 37$ & 0.268 & 0.077 & $0 \cdot 30$ \\
\hline Citric & 0.277 & 0.206 & 0.74 & $0 \cdot 260$ & 0.311 & $\mathbf{1} \cdot \mathbf{1 0}$ \\
\hline Formic & 0.074 & $0 \cdot 030$ & 0.41 & 0.088 & 0.020 & $0 \cdot 23$ \\
\hline Fumaric & 0.409 & $0 \cdot 197$ & 0.48 & $\mathbf{0 . 3 8 8}$ & 0.297 & 0.76 \\
\hline Lactic & - & - & - & 0.294 & $0 \cdot 197$ & $0 \cdot 67$ \\
\hline L-Malic & $0 \cdot 285$ & $0 \cdot 185$ & $0 \cdot 68$ & $\mathbf{0} \cdot \mathbf{2 6 8}$ & 0.266 & $1 \cdot 00$ \\
\hline$\alpha-O x o g l u t a r i c$ & 0.242 & $0 \cdot 0$ & $0 \cdot 0$ & 0.234 & 0.0 & $0 \cdot 0$ \\
\hline Succinic & 0.285 & $0 \cdot 150$ & $0 \cdot 71$ & $0 \cdot 294$ & 0.210 & $0 \cdot 71$ \\
\hline
\end{tabular}

Effect of organic acids. These were studied in tube tests in medium I with and without lactate. The results (Table 1) show that, with the exception of citrate and L-malate, all the acids tested inhibited 'amine' formation per unit cell weight in both media. $\alpha$-Oxoglutarate $(0.05 \mathrm{M})$ completely inhibited the formation of 'amine' but only slightly inhibited growth. Formate inhibited growth and 'amine' formation, whilst fumarate stimulated growth but had no effect on the level of 'amine'.

Organisms grown in the presence of $0.05 \mathrm{M} \alpha$-oxoglutarate lacked the pink colour invariably associated with those harvested from culture filtrates containing 'amine'. However, the concentration of $\alpha$-oxoglutarate $(0.05 \mathrm{M})$ required completely to prevent the formation of 'amine' was much greater than that of adenine $(0.0037 \mathrm{M})$ or of L-asparate $(500 \mu \mathrm{g} . / \mathrm{ml}$. or $0.0038 \mathrm{M}$, Fig. 2) required to produce the same result.

The effect of lactate, which is a normal constituent of the medium used for 'amine' formation, requires special mention. Omission of lactate led to the accumulation of appreciably greater concentrations of 'amine' and appeared to offer a means by which increased yields of 'amine' might be obtained. However, tests on the culture vessel scale showed that the amount of 'amine' precipitable by mercuric acetate from lactate-free media was only one-third 
that obtained from media with lactate. Lactate was therefore retained as a constituent of the medium used for 'amine' preparation. Citrate was ineffective in replacing lactate in this respect.

\section{Effect of aspartate on the accumulation of 'amine' and hypoxanthine}

Effect on 'amine'. Chamberlain \& Rainbow (1954) showed that the addition of $500 \mu \mathrm{g}$. of $\mathrm{L}$-aspartic acid/ml. to a culture of yeast 47 grown under conditions otherwise suitable for 'amine' formation almost completely prevented 'amine' accumulation. Table 2 shows that D-aspartic acid was also effective in this respect, but, unlike the L-isomer, it had no effect on the course of growth.

\section{Table 2. Effect of aspartate on growth of, and 'amine' formation} by, yeast $\mathbf{4 7}$

Tube tests in medium I at $\mathbf{2 5}^{\circ}$; growth as mg. yeast dry weight/ml.; 'amine' as Spekker readings of the colour produced from unpurified culture filtrates in the diazotization reaction; aspartic acid supplements (adjusted to $\mathrm{pH} \mathrm{5.0} \mathrm{with} \mathrm{KOH}$ solution), $500 \mu \mathrm{g}$. of the $\mathrm{D}-, \mathrm{L}$ - or $\mathrm{DL}$ - forms/ml.

\begin{tabular}{|c|c|c|c|c|c|}
\hline \multirow{3}{*}{$\begin{array}{l}\text { Aspartic acid } \\
\text { supplement }\end{array}$} & \multicolumn{4}{|c|}{ Growth } & \multirow{3}{*}{$\begin{array}{c}\text { 'Amine' } \\
96 \mathrm{hr} .\end{array}$} \\
\hline & \multicolumn{4}{|c|}{ Time (hr.) } & \\
\hline & 24 & 48 & 72 & 96 & \\
\hline Nil & 0.023 & $0 \cdot 108$ & 0.187 & $0 \cdot 268$ & $0 \cdot 212$ \\
\hline L- & $0 \cdot 136$ & $0 \cdot 187$ & $0 \cdot 187$ & $0 \cdot 187$ & 0.059 \\
\hline D- & 0.028 & 0.122 & 0.187 & 0.268 & 0.069 \\
\hline DL- & $0 \cdot 129$ & $0 \cdot 202$ & $0 \cdot 194$ & $0 \cdot 194$ & 0.058 \\
\hline
\end{tabular}

The minimum concentration of $L$-aspartic acid necessary to effect maximum inhibition of 'amine' formation was $c .500 \mu \mathrm{g} . / \mathrm{ml}$. (Fig. 2). The same experiment showed that much smaller concentrations $(c .30 \mu \mathrm{g} . / \mathrm{ml}$.) of L-aspartic acid stimulated 'amine' accumulation.

Effect on hypoxanthine. Cultures $(500 \mathrm{ml}$.) of yeast 47 in medium I and in medium I supplemented with $500 \mu \mathrm{g}$. of L-aspartic acid $/ \mathrm{ml}$. were grown at $21^{\circ}$ for 5 days. After removing the cells, a concentrate containing all the 'amine' and hypoxanthine was prepared from each culture by precipitation with mercuric acetate at $\mathrm{pH} 4 \cdot 4$, decomposition of the mercury complex with $\mathrm{H}_{2} \mathrm{~S}$ and concentration of the resultant solution, as in the usual procedure for preparing 'amine'. Ultraviolet spectroscopy showed that, in the presence of L-aspartic acid, a material with $E_{\max } .256 \mathrm{~m} \mu$ accumulated, whereas in the absence of $L$-aspartate a material, presumably hypoxanthine (Chamberlain \& Rainbow, 1954) with $E_{\max .} 250 \mathrm{~m} \mu$ was obtained. Paper chromatography revealed that no spot corresponding to hypoxanthine was given by the concentrate derived from the aspartate-supplemented culture. Instead, ultraviolet-absorbing substances, which were absent from the concentrate derived from the unsupplemented culture, were present. One of these substances had a chromatographic mobility considerable greater than that of hypoxanthine, and at least three others had mobilities much less than that of hypoxanthine. These new ultraviolet-absorbing substances were also chromatographically distinct from adenine and guanine. 
A portion (1 ml.) of a concentrate obtained from an aspartate-supplemented culture was hydrolysed with $1 \mathrm{~N}-\mathrm{H}_{2} \mathrm{SO}_{4}$ for $2 \mathrm{hr}$. at $100^{\circ}$; after neutralizing with $\mathrm{Ba}(\mathrm{OH})_{2}$ and centrifuging, the supernatant was evaporated in vacuo to $1 \mathrm{ml}$. This solution contained free reducing sugar, and paper chromatography showed that the ultraviolet-absorbing substances of the unhydrolysed concentrate had been replaced by a single spot, chromatographically identical with adenine. This spot, and one of authentic adenine,

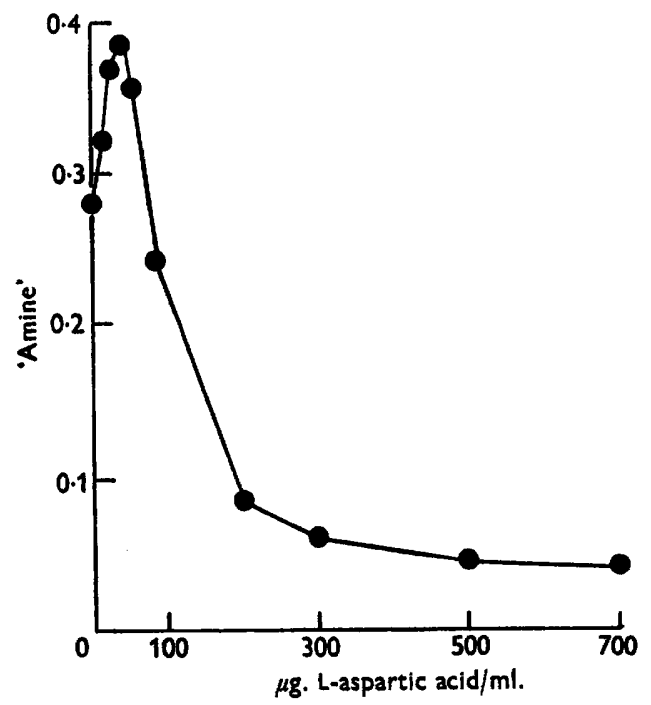

Fig. 2. Effect of concentration of L-aspartic acid on 'amine' formation. Tube tests in medium II at $21^{\circ}$ for 5 days; 'amine' as Spekker readings of the colour produced from unpurified culture flitrates in the diazotization reaction.

were eluted from the paper and examined spectrophotometrically; both materials exhibited peak absorption at $262 \mathrm{~m} \mu$ and their absorption ratios, measured at $5 \mathrm{~m} \mu$ intervals between 235 and $290 \mathrm{~m} \mu$, were the same within $2 \%$. The ultraviolet absorbing substances in the hydrolysate therefore appeared to be adenine, from which it may be inferred that the new ultravioletabsorbing substances which accumulated in cultures containing L-aspartate were derivatives of adenine.

Effects of other substances. The inhibitory effects of norleucine, norvaline, adenine and aspartic acid on 'amine' formation were described by Chamberlain \& Rainbow (1954). Tube tests in medium $I$ at $21^{\circ}$ for 5 days showed that the addition of single pyrimidines $(25 \mu \mathrm{g}$. $/ \mathrm{ml}$. of uracil, thymine, cytosine or orotic acid) enhanced 'amine' formation by $c .5-10 \%$, but growth was unaffected. When all the pyrimidines were present together, 'amine' formation was enhanced by $c .20 \%$.

\section{Preparation of 'purified amine'}

The early stages of the preparation were based on the procedure of Chamberlain \& Rainbow (1954) with the following modifications: $(a)$ medium II was used, each culture vessel containing $500 \mathrm{ml}$., and (b) each culture was inocu- 
latea with $1 \mathrm{ml}$. of washed yeast suspension. 'Amine' was precipitated with mercuric acetate and the precipitate washed as previously described. The washed precipitate from each culture was then shaken into suspension in $32.5 \mathrm{ml}$. of $0.001 \mathrm{~N}-\mathrm{H}_{2} \mathrm{SO}_{4}$ and decomposed by passing water-washed $\mathrm{H}_{2} \mathrm{~S}$ through the supension for $45 \mathrm{~min}$. After removing excess $\mathrm{H}_{2} \mathrm{~S}$ in a vigorous current of air, the $\mathrm{pH}$ was adjusted to a value of $c .9 \cdot 0$ with $3.5 \mathrm{ml}$. of saturated $\mathrm{Ba}(\mathrm{OH})_{2}$. The precipitate (containing $\mathrm{HgS}, \mathrm{BaSO}_{4}$ and $\mathrm{Ba}_{3}\left(\mathrm{PO}_{4}\right)_{2}$ ) was removed by centrifuging, washed once with distilled water and the combined supernatants adjusted to $\mathrm{pH} 4.0$ with $4.5 \mathrm{ml}$. of $0.1 \mathrm{~N}-\mathrm{H}_{2} \mathrm{SO}_{4}$. The 'amine' solution, obtained after centrifuging off and washing the $\mathrm{BaSO}_{4}$ thus precipitated, contained (as judged by diazotizability) $85 \%$ of the 'amine' present in the original culture filtrate and was stable on storage for 6 weeks at $\mathrm{pH} 4.0$ at $4^{\circ}$. This improved recovery of 'amine' [Chamberlain \& Rainbow (1954) obtained only a $49 \%$ recovery] appeared to be chiefly the result of the treatment at $\mathrm{pH} 9 \cdot 0$, which effected desorption of ' amine' from the $\mathrm{HgS}$ precipitated at $\mathrm{pH} 4 \cdot 0$. At this stage, the 'amine' solution contained also hypoxanthine, amino acids (chiefly methionine) and the anions sulphate and acetate, but not phosphate.

The 'amine' was separated from these contaminants on ion exchange resins. The 'amine'-containing solution ( $\mathrm{pH} 4.0)$, derived from one $500 \mathrm{ml}$. culture, was percolated, at a flow rate of $100 \mathrm{ml} / \mathrm{hr}$. through a column $(40 \times 1.6 \mathrm{~cm}$.) containing $50 \mathrm{~g}$. of Amberlite IRC-50 resin in the hydrogen form. This was followed by distilled water at the same rate until $250 \mathrm{ml}$. of total effluent had collected. Distilled water (1 1 .) was then passed through the column at the rate of $200 \mathrm{ml}$. $/ \mathrm{hr}$. After ensuring that the optical density at $250 \mathrm{~m} \mu$. of the last runnings of this effluent (which contained the hypoxanthine) was at a constant low level, the outlet jet of the column was immediately connected to the top of a column $(9 \times 1.1 \mathrm{~cm}$.) containing $3 \mathrm{~g}$. of $\mathrm{Amber}$ lite IR-4 B resin in the hydroxyl form and $400 \mathrm{ml}$. of $0.005 \mathrm{~N}-\mathrm{HCl}$ was allowed to flow through both resin beds in series at a flow rate of $200 \mathrm{ml} . / \mathrm{hr}$. Very dilute acid was used for this elution since it was known that 'amine' was particularly labile under acid conditions, treatment with $0.01 \mathrm{~N}-\mathrm{HCl}$ for $2 \mathrm{hr}$. causing a $23 \%$ loss of diazotizability. The acid-free effluent was concentrated in vacuo at less than $35^{\circ}$ to yield a yellowish, crystalline residue (6.5-15 mg. from each $500 \mathrm{ml}$. of original culture). This material, subsequently referred to as 'purified amine', was shown by paper chromatography to be substantially free from amino acids, and by ultraviolet spectroscopy to be free from hypoxanthine. 'Purified amine' was stored in vacuo in the dark; it became darker in colour on storage, especially if air was admitted.

Overall recoveries of 'amine' as 'purified amine' varied from about $30 \%$ to. $80 \%$ as judged by diazotizability. Losses may have been caused by decomposition of 'amine' on the resin columns. Attempts to purify 'amine' further have been hampered by its lability, especially in the presence of air, in aqueous. solutions having $\mathrm{pH}$ values outside the range $\mathrm{pH}$ 4-6. It has not been possible to recover 'amine' from sorption on resins other than weakly acidic cation exchangers and relatively little 'amine' survived chromatographic separation on columns of cellulose powder developed with $n$-butanol + acetic acid + water. 


\section{Analysis of 'purified amine'}

Pentose content. Chamberlain \& Rainbow (1954) have already suggested that 'amine' is implicated in purine biosynthesis and, since it is widely accepted that the latter proceeds at the nucleoside or nucleotide level, 'amine' was tested for pentose as follows.

(i) 'Purified amine' gave a positive reaction for pentose in the orcinol test.

(ii) No colour was formed when $400 \mu \mathrm{g}$. of 'purified amine' dissolved in $2 \mathrm{ml}$. of water was heated at $100^{\circ}$ for $10 \mathrm{~min}$. in Dische's (1955) test for 2-deoxypentoses. D-Ribose $(50 \mu \mathrm{g})$ also failed to give the reaction, but $50 \mu \mathrm{g}$. of authentic D-2-deoxyribose gave a strong blue colour under the same conditions.

(iii) Pentose was present in 'purified amine' in a combined, non-reducing form, since $50 \mu \mathrm{g}$. of 'purified amine' as a spot on filter paper gave no pink colour when treated with aniline hydrogen phthalate at $100^{\circ}$.

(iv) $5 \mathrm{mg}$. of 'purified amine' was hydrolysed with $2 \mathrm{ml}$. of $1 \mathrm{~N}-\mathrm{H}_{2} \mathrm{SO}_{4}$ at $100^{\circ}$ for $2 \mathrm{hr}$. The hydrolysate was neutralized with $\mathrm{Ba}(\mathrm{OH})_{2}$ to $\mathrm{pH} 6.5$, centrifuged and the supernatant evaporated in vacuo at $35^{\circ}$ to $c .0 .25 \mathrm{ml}$. This hydrolysate was not diazotizable by the Bratton \& Marshall procedure, but it contained reducing sugar. The hydrolysate $(20 \mathrm{ml}$.) was then chromatographed on paper with reference spots containing $10 \mu \mathrm{g}$. each of D-ribose, D-xylose and L-arabinose according to the procedure of Giovannozzi-Sermanni (1956). The spots, revealed by aniline phthalate, showed that the chromatographic mobility of the reducing sugar present in the hydrolysate corresponded closely with that of $\mathrm{D}$-ribose.

Phosphate content. No phosphate was detected in 'purified amine' after digestion with $\mathrm{HClO}_{4}$ according to the procedure of Allen (1940).

Pauly test. If, as suggested by Chamberlain \& Rainbow (1954), 'amine' possesses an incomplete purine structure, it may be an imidazole derivative similar in structure to the recognized purine precursor, 4(5)-amino-5(4)-imidazolecarboxamide (AICA), from which, however, 'amine' is distinct (Chamberlain \& Rainbow, 1954). The possible presence of the imidazole nucleus in 'amine' was therefore examined by application of the Pauly reaction. In this reaction, $50 \mu \mathrm{g}$. of 'purified amine' gave a purple colour, which faded within 5 min. to yellow similar to the blank. Under similar conditions, $40 \mu \mathrm{g}$. of histidine gave a permanent red colour and $40 \mu \mathrm{g}$. of AICA gave a permanent blue colour. Hypoxanthine $(100 \mu \mathrm{g}$.) gave no reaction. The colour given by 'amine', although transitory, confirms the presence of the imidazole nucleus: a transitory colour is given by other imidazoles such as 4-ureido-5-imidazolecarboxylic acid (Rabinowitz \& Pricer, 1956) and 5-aminoimidazole ribotide (Levenberg \& Buchanan, 1957). That the substance giving the transient Pauly reaction was identical with the diazotizable substance was indicated by paper chromatography in which two spots of 'purified amine' (100 $\mu$ g. each) were run side by side: after development in $n$-butanol + acetic acid+water (Chamberlain \& Rainbow, 1954), the paper was cut longitudinally and one half sprayed with Bratton \& Marshall reagents and the other with Pauly reagents. This procedure showed that the diazotizable sub- 
stance and that giving a transient colour in the Pauly reaction were chromatographically identical.

Products of acid hydrolysis. $5 \mathrm{mg}$. of 'purified amine' was hydrolysed under reflux with $2 \mathrm{ml}$. of $1 \mathrm{~N}-\mathrm{H}_{2} \mathrm{SO}_{4}$ for $2 \mathrm{hr}$. at $100^{\circ}$. After adjustment to $\mathrm{pH} \mathrm{6.5}$ with saturated $\mathrm{Ba}(\mathrm{OH})_{2}$ solution and centrifuging, the clear supernatant was evaporated in vacuo to dryness at $40^{\circ}$ and the residue was taken up in $0.25 \mathrm{ml}$. of distilled water. Portions of this solution were examined as follows.

(i) Paper chromatography (20 $\mu$ l. spots) in $n$-butanol + acetic acid + water revealed only one ninhydrin-reacting spot corresponding either to glycine or to serine. Further examination in a phenol + water solvent distinguished this material as glycine and not serine. Its identity as glycine was confirmed since the acid hydrolysate of 'purified amine' substituted for glycine, but not for serine, in the growth of Lactobacillus brevis $\mathrm{L} 4$ which requires both amino acids. By microbiological assay with $\mathrm{L} 4$, the approximate amount of glycine obtained after hydrolysing $\mathbf{2} \cdot \mathbf{4} \mathrm{mg}$. of a preparation of 'purified amine' was determined as $252 \mu \mathrm{g}$. (Table 3 ).

Table 3. Analysis of 'purified amine'

Except as indicated, analytical methods were as described in the 'Methods' section. Figures in the column headed ' $\mu$ mole' are calculated on an ash-free basis.

Preparation no.

\begin{tabular}{|c|c|c|c|c|c|c|c|c|}
\hline & \multicolumn{2}{|c|}{ I } & \multicolumn{2}{|c|}{ II } & \multicolumn{2}{|c|}{ III } & \multicolumn{2}{|c|}{ IV } \\
\hline & $\mu \mathrm{g}$. & $\mu$ mole & $\mu \mathrm{g}$ & $\mu$ mole & $\mu \mathrm{g}$ & $\mu$ mole & $\mu \mathrm{g}$ & $\mu \mathrm{mole}$ \\
\hline 'Purified amine' & 2400 & 一 & 13220 & - & 19910 & - & 29510 & - \\
\hline Ash & 1005 & - & 2751 & - & 5595 & - & 4604 & - \\
\hline Ribose & 314 & $\mathbf{2} \cdot \mathbf{1}$ & 5360 & 36 & 2850 & 19 & 2387 & 16 \\
\hline Formic acid & - & - & - & - & 1991 & 44 & 2401 & 52 \\
\hline Total-N & - & - & 1872 & 134 & 2528 & 181 & 5774 & 4,12 \\
\hline Ammonia-N & $142 *$ & $10 \cdot 1$ & 1443 & 103 & 1764 & 126 & 4900 & 350 \\
\hline Glycine-N & $47 \dagger$ & $3 \cdot 4$ & 429 & 31 & 764 & 55 & 874 & 62 \\
\hline
\end{tabular}

(ii) The presence of ammonia in the hydrolysate was shown with Nessler's reagent. By comparing the colour produced in this reaction with that produced from known ammonium chloride standards, the approximate amount of ammonia-N yielded by acid hydrolysis of 'purified amine' was determined (Table 3).

(iii) Three drops of the hydrolysate were acidified and then reduced by adding magnesium powder. The reduced product gave a positive chromotrophic acid test for formaldehyde.

The results described in (i) and (ii) above showed that acid hydrolysis of 'purified amine' yielded glycine and ammonia. There was also evidence [(iii) above] that formic acid was also produced. The formation of these products, known to arise by hydrolytic degradation from certain imidazole derivatives (Hunter, 1936), is confirmation that the imidazole nucleus may form part of the structure of 'amine'.

Chromatographic behaviour. When relatively large amounts (50-60 $\mu \mathrm{g}$.$) of$ 
'purified amine' were chromatographed on paper, a second material, showing as a less intense red spot in the diazotization reaction, was apparent just below the main constituent. By development in $n$-butanol + acetic acid + water $(4: 1: 5)$, the smaller spot became well separated from the larger one. That glycosidically bound pentose was associated only with the larger spot was shown by spraying replicate chromatograms with (i) $1 \%$ lead tetraacetate in benzene and (ii) aniline hydrogen phthalate. The material having a chromatographic mobility identical with the larger diazotizable spot gave a positive reaction in test (i), but test (ii) was negative, showing that neither material contained free reducing sugar.

Ultraviolet absorption. Figure 3 shows the ultraviolet absorption curve of 'purified amine'. The curve has a feeble peak at $238 \mathrm{~m} \mu$.

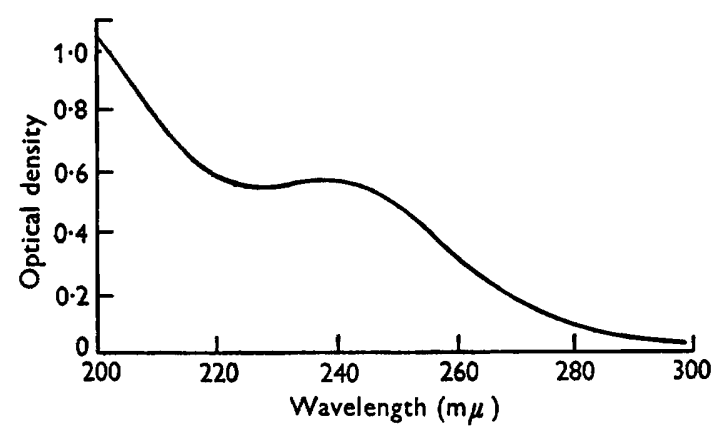

Fig. 3. Ultraviolet absorption curve of 'purified amine' (105 $\mu \mathrm{g} . / \mathrm{ml}$.) in aqueous solution.

\section{Quantitative analyses of 'purified amine'}

Table 3 gives some representative results of analyses of preparations of 'purified amine' Because of the instability of 'amine', analyses were performed on freshly prepared samples or on samples which had been stored in vacuo not longer than $24 \mathrm{hr}$.

The analyses show that the composition of 'purified amine' varies from preparation to preparation. Nevertheless, on acid hydrolysis, all preparations yielded substantial amounts of ribose, formate, ammonia and another nitrogen compound, presumed to be glycine from the evidence of paper chromatography and microbiological assay. Formate, ammonia and glycine are the products of acid hydrolysis of 5(4)-amino-imidazole (Hunter \& Nelson, 1941). The presence of ribose in the hydrolysis products suggests that 'amine' may occur as the riboside of $5(4)$-amino-imidazole, but the expected molar ratios of ribose:formate:glycine:ammonia:(1:1:1:2) are not realized in our analytical figures. On an ash-free basis, the molar proportions of glycine:formate in samples so far analysed for both of these substances (e.g. preparations nos. III and IV in Table 3) have proven to be approximately $1: 1$. However, the values for ammonia- $\mathrm{N}$ are too high and those for ribose are usually too low. Low values for ribose are possibly attributable to the presence in 'purified amine' of 'amine', not in the riboside form. This possibility is supported by the evidence of the chromatographic behaviour of 'purified amine'. 
Preparations of 'purified amine' contained $15-45 \%$ of ash, presumably derived from the IR-4B resin. Despite prolonged washing difficulty was always experienced in obtaining neutral effluents after regenerating the resin. It may be noted that Levenberg \& Buchanan (1957) found that their 5-aminoimidazole ribotide, prepared, like our 'amine', by a method involving ion exchange, was 35-60\% pure, and they believed that the chief impurity was inorganic salts.

Our results suggest that our preparations usually contain both 'amine' and 'amine' riboside, contaminated with mineral and ammonium salts, the latter arising possibly from decomposition of 'amine' on the columns.

As judged by its diazotizability, preparation III (Table 3) contained $59 \%$ of the total 'amine' of the original culture filtrate. Calculations based on the formic acid figure show that the culture filtrate contained c. $6 \mu \mathrm{g}$. 'amine' (as 5-amino-imidazole)/ml.

\section{DISCUSSION}

Although 'amine' was not obtained pure, its lability and the evidence derived from its behaviour ( $a$ ) in the Bratton \& Marshall reaction; $(b)$ in the Pauly reaction and $(c)$ on acid hydrolysis, indicate that the chief diazotizable constituent of 'purified amine' is 5-amino-imidazole riboside or a compound closely related to it. Chamberlain \& Rainbow (1954) showed that maximum absorption of the azo colour produced when 'amine' underwent the Bratton \& Marshall reaction occurred at $500 \mathrm{~m} \mu$, a value which is similar to that quoted by Levenberg \& Buchanan (1957) for 5-amino-imidazole ribotide and by Love \& Gots (1955) for an amino-imidazole riboside isolated from culture fluids of a purine-less mutant of Escherichia coli. This absorption maximum serves to distinguish 'amine' from 4(5)-amino-5(4)-imidazolecarboxamide, the azo colour from which absorbs maximally at $540 \mathrm{~m} \mu$.

A number of known imidazoles yield glycine, ammonia and formic acid on acid hydrolysis (Hunter \& Nelson, 1941; Hofmann, 1953). The formation of these products depends upon positions 1, 2 and 4 (or 5) being either unoccupied or occupied by labile substituents. Thus, 4(5)-amino-5(4)-imidazolecarboxylic acid yields $\mathrm{CO}_{2}$ in addition to these products (Rabinowitz, 1956) but 4 (5)-amino-5(4)-methylimidazole yields $\alpha$-alanine, ammonia and formic acid (Fargher, 1920).

It therefore seems reasonable to believe that the diazotizable moiety of 'amine' is 5(4)-amino-imidazole. The diazotizable amino group is likely to be on position 4 (or 5 ) since the 1- and 2-amino derivatives of imidazole are not diazotizable (Hofmann, 1953) and, in any case, position-1 of 'amine', by analogy with known nucleosides, may be occupied by ribose:

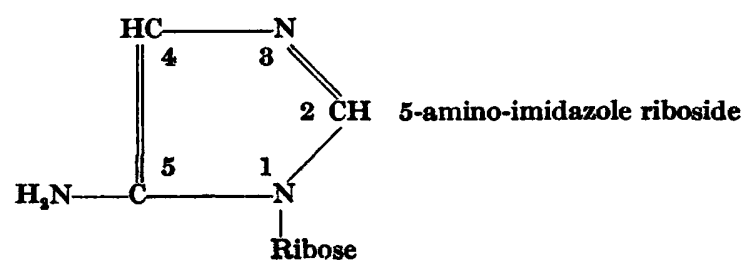


The analytical figures (Table 3) show that the amounts of ribose, ammonia, formate and glycine are inadequate to account for all the material present in ash-free 'purified amine'. The discrepancy may be accounted for either by the presence of volatile salts in the preparation, or by the presence of an undetected labile substituent in position-4 (or 5) Such a substituent might be a carboxyl group, although this seems unlikely because of the behaviour of 'amine' on ion exchange resins.

The paper chromatographic behaviour of 'purified amine' suggests that the preparations contain diazotizable material both in the free and riboside forms. Both forms may be present in the original culture filtrates or free diazotizable amine may arise by rupture of the glycosidic bond during isolation. The diazotizable aglycone presumably would be retained by the resin and would appear in the final product together with the riboside.

The present work confirms the view of Chamberlain \& Rainbow (1954) that the accumulation of 'amine' is a sympton of a disordered purine metabolism in yeast 47 . Since the biosynthesis and transformations of purines are recognized to occur at the nucleoside or nucleotide level, it is not surprising that 'amine' is a riboside. The metabolic defect in question appears to be mainly an inability to aminate hypoxanthine to adenine.

The accumulation of 'amine' in cultures of yeast 47 is prevented by the addition of adenine or of aspartate (Chamberlain \& Rainbow, 1954). The present work shows that, when 'amine' formation is depressed by addition of aspartate, adenine derivatives accumulate instead of hypoxanthine. These facts suggest that the accumulation of 'amine' and hypoxanthine by yeast 47 is the result of a biotin-conditioned deficiency of aspartic acid. In this connexion, the involvement of biotin in aspartate metabolism has been established for yeast (Winzler, Burk \& du Vigneaud, 1944) and for lactic acid bacteria (Broquist \& Snell, 1951), whilst Lichstein \& Umbreit (1947) have established a role for biotin in amination reactions leading to aspartate formation. In yeast 47 , aspartate may be the donor of the amino group attached to position-6 of the purine skeleton by means of which hypoxanthine is converted to adenine in reactions occurring presumably at the riboside or ribotide level. The following biosynthetic sequence may represent the course of events in yeast 47 :

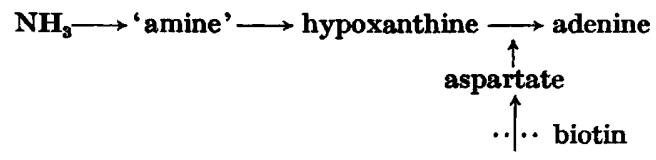

Other recent work supports the contention that aspartic acid is involved in the conversion of derivatives of hypoxanthine to derivatives of adenine: thus Abrams \& Bentley (1955) showed that aspartate was required for the amination of inosinic acid to adenylic acid by rabbit bone marrow. Again, Lieberman (1956) showed that in the transformation of inosine $5^{\prime}$-phosphate to adenosine $5^{\prime}$-phosphate by extracts of Escherichia coli, adenylosuccinic acid (6-aspartylpurine nucleotide), already isolated by Carter \& Cohen (1955) with the aid of an enzymic extract obtained from baker's yeast, was intermediate. 
In addition to its role in the biochemical transformation of purine derivatives, aspartate also contributes the nitrogen in position-1 of the purine skeleton (Levenberg, Hartman \& Buchanan, 1956).

The present results fit in well with current ideas of purine biosynthesis by Levenberg \& Buchanan (1957). The properties of 'amine' resemble closely those of 5-amino-imidazole investigated by those workers and those of the diazotizable amines, considered to have a similar structure, examined by Love \& Gots (1955) and by Moat, Wilkins \& Friedman (1956).

We are indebted to the Brewer's Society for a grant to D.P.L., to the D.S.I.R. for a grant to J.D.W., and to Dr A. B. Foster, Chemistry Department, University of Birmingham, for a gift of D-2-deoxyribose.

\section{REFERENCES}

Abrams, R. \& Bentrey, M. (1955). Transformation of inosinic acid to adenylic and guanylic acids in a soluble enzyme system. J. Amer. chem. Soc. 77, 4179 .

Aluen, R. J. L. (1940). The estimation of phosphorus. Biochem. J. 34, 858.

Ames, B. N. \& Mitcheld, H. K. (1952). The paper chromatography of imidazoles. J. Amer. chem. Soc. 74, 252.

Broquist, H. P. \& Snell, E. E. (1951). Biotin and bacterial growth. I. Relation to aspartate, oleate and carbon dioxide. J. biol. Chem. 188, 431.

CARTER, C. E. \& Cohen, L. H. (1955). Enzymatic synthesis of adenylosuccinic acid. J. Amer. chem. Soc. 77, 499.

Chamberlain, N., Cutts, N. S. \& Rainbow, C. (1952). The formation of pigment and arylamine by yeasts. J. gen. Microbiol. $7,54$.

Chamberlayn, N. \& Rainbow, C. (1954). The formation of diazotizable amine and hypoxanthine by a yeast: possible implications in the biosynthesis of purines. J. gen. Microbiol. 11, 80.

Dische, Z. (1955). In The Nucleic Acids, vol. 1, p. 287. New York: Academic Press.

DruRy, H. F. (1948). Identification and estimation of pentoses in the presence of glucose. Arch. Biochem. 19, 455.

FARGmer, R. G. (1920). Orientation of the nitro- and arylazo-glyoxalines. Fission of the glyoxalone nucleus. J. chem. Soc. 117, 668 .

Giovannozzi-Sermanni, G. (1956). A new solvent for quantitative chromatography of sugars. Nature, Lond. 177, 586.

Hofmann, J. (1953). Chemistry of the Heterocyclic Compounds, vol. 6. New York: Arnold.

HunTER, G. (1936). On the hydrolysis of guanine. Biochem. J. 30, 1183.

Hunter, G. \& Nelson, J. A. (1941). On 4-(or 5-) aminoglyoxaline (imidazole). Canad. J. Res. (Sect. B), 19, 296.

Koessler, K. K. \& HANKE, M. T. (1919). Studies on proteinogenous amines. II. A microchemical colorimetric method for estimating imidazole derivatives. $J$. biol. Chem. 39, 497.

Levenberg, B. \& Buchanan, J. M. (1957). Biosynthesis of the purines. XII. Structure, enzymatic synthesis, and metabolism of 5-amino-imidazole ribotide. $J$. biol. Chem. 224, 1005.

Levenberg, B., Hartman, S. C. \& Buchanan, J. M. (1956). Biosynthesis of the purines. $\mathrm{X}$. Further studies in vitro on the metabolic origin of nitrogen atoms 1 and 3 of the purine ring. J. biol Chem 220, 379.

Lichstein, H. C. \& Umbreit, W. W. (1947). Biotin activation of certain deaminases. J. biol. Chem. 170, 423. 
LIEBERMAN, I. (1956). Involvement of guanosine triphosphate in the synthesis of adenylosuccinate from inosine-5' -phosphate. J. Amer. chem. Soc. 78, 251.

Love, S. H. \& Gots, J. S. (1955). Purine metabolism in bacteria. III. Accumulation of a new pentose-containing arylamine by a purine-requiring mutant of Escherichia coli. J. biol. Chem. 212, 647.

Moat, A. G., Wilkins, C. N. \& Friedman,.H. (1956). A role for biotin in purine biosynthesis. J. biol. Chem. 223, 985.

Moore, W. B. \& RAINBow, C. (1955). Nutritional requirements and biochemical activities of brewery lactobacilli. J. gen. Microbiol. $13,190$.

Northam, B. E. \& NorRIs, F. W. (1951). Growth requirements of Schizosaccharomyces octosporus, yeast exacting towards adenine. J. gen. Microbiol. 5, 502.

Rabinowitz, J. C. (1956). Purine fermentation by Clostridium cylindrosporum. III. 4-Amino-5-imidazole-carboxylic acid and 4-aminoimidazole. J. biol. Chem. $218,175$.

Rabinowtiz, J. C. \& Pricer, W. E. Jr. (1956). Purine fermentation by Clostridium cylindrosporum. IV. 4-Ureido-5-imidazolecarboxylic acid. J. biol. Chem. 218, 189.

Winzler, R. J., Burk, D. \& du Vigneaud, V. (1944). Biotin in fermentation, respiration, growth and nitrogen assimilation by yeast. Arch. Biochem. 5, 25. 